\title{
Evolutionary variations on a theme: host plant specialization in five geographical populations of the leaf beetle Chrysomela lapponica
}

\author{
Elena L. Zvereva $\cdot$ Mikhail V. Kozlov $\cdot$ \\ Monika Hilker
}

Received: 20 August 2009/Accepted: 11 December 2009/Published online: 17 March 2010

(C) The Society of Population Ecology and Springer 2010

\begin{abstract}
The ancestral host plants of Chrysomela lapponica are Salicaceae rich in salicylic glycosides (SGs), which serve as precursors for larval chemical defensive secretions. Nevertheless, some populations have shifted to plants poor in SGs or even lacking these compounds. To study whether this shift is accompanied by adaptations to novel SG-poor host plants, we reared C. lapponica larvae from five geographical populations on host plants with high (Salix myrsinifolia) or low (S. caprea) SG content. Individuals from two populations (Finland and Kola region in Russia) associated in nature with SG-rich S. myrsinifolia showed higher survival and shorter developmental time on native host species than on foreign SG-poor S. caprea, thus demonstrating local adaptations to their ancestral SG-rich host plant. Individuals from a Belarus population associated in nature with SG-poor $S$. caprea showed higher survival on this species than on foreign SG-rich $S$. myrsinifolia, thus demonstrating local adaptation to the novel SG-poor host. On the other hand, individuals from two other populations associated in nature with SG-poor plants (Baikal and Ural region) performed equally well on both SG-rich S. myrsinifolia and SG-poor S. caprea in our rearing experiments, thus showing no local adaptation to a specific SG-host type, but rather a wide feeding niche including several Salicaceae species of different SG-type. Our results suggest that diet breadth of $C$. lapponica is a local phenomenon, and that adaptation strategies to novel
\end{abstract}

E. L. Zvereva $(\bowtie) \cdot$ M. V. Kozlov

Section of Ecology, Department of Biology,

University of Turku, 20014 Turku, Finland

e-mail: elezve@utu.fi

M. Hilker

Institute of Biology, Freie Universität Berlin,

Haderslebener Str. 9, 12163 Berlin, Germany host plants may differ between populations of a single leaf beetle species.

Keywords Herbivore specialization - Host shift . Local adaptation $\cdot$ Performance $\cdot$ Survival $\cdot$ Willow

\section{Introduction}

The tendency to specialize on one or a few plant species is likely a major reason for the remarkable diversity of herbivorous insect species (Futuyma and Moreno 1988; Jaenike 1990; Egas et al. 2005). Conservative host plant association of specialized insects was often thought to lead to an evolutionary dead end (Mayr 1963; Rensch 1980; but see Kelley and Farrell 1998). Herbivorous leaf beetles (Chrysomelidae), one of the largest groups of plant-feeding insects, generally show high levels of host plant specialization (Futuyma and McCafferty 1990; Funk et al. 1995; Fernandez and Hilker 2007). Nevertheless, shifts from one host plant species, genus, or even family to another one do frequently occur (Dobler et al. 1996; Termonia and Pasteels 1999). These host shifts offer opportunities to investigate the evolutionary forces driving host plant specialization (Camara 1997), and leaf beetles are valuable models in exploring the evolution of host use (Termonia et al. 2001; Margraf et al. 2007).

Host plant fidelity in herbivores is influenced by several life history traits. One of the most important factors is protection against natural enemies through host-specific crypsis or sequestered host-derived defensive chemicals (Bernays and Graham 1988). A number of leaf beetle species (many Chrysomela spp. and Phratora vitellinae L.) are specialized to feed upon salicaceous host plants. Many of these plants contain high contents of phenolic glycosides 
deterring non-specialized herbivores from feeding. Phenolic glycosides provide the precursor for the major component of the larval defensive secretion of Chrysomela spp. and $P$. vitellinae, i.e., salicylaldehyde from salicylic glycosides (SGs; i.e., salicin and salicortin) present in host plant leaves (Pasteels et al. 1983). Advantages of this specialization to SG-rich plants are obvious and include avoidance of competition with herbivores not adapted to SG-rich host plants as well as protection from generalist natural enemies through low-cost defense systems based on sequestered plant components (Smiley et al. 1985; RowellRahier and Pasteels 1986; Kearsley and Whitham 1992).

Considering these advantages, shifts back to host plants not containing SGs are indeed surprising. Leaf beetle species exhibiting such shifts generally belong to the Chrysomela interrupta group (sensu Brown 1956). Larvae of this group are able to produce their defensive secretion through a combination of sequestration of plant compounds and autogenous biosynthesis, and both sequestered and synthesized components are repellents for generalist natural enemies (Hilker and Schulz 1994; Schulz et al. 1997). The ability to produce defensive secretions de novo decreases the beetle's dependence on host plant chemicals and allows specialized species to broaden their host range using plants lacking precursors for sequestering the defensive secretion compounds (Soetens et al. 1998; Termonia and Pasteels 1999; Termonia et al. 2001).

The leaf beetle $C$. lapponica $\mathrm{L}$. belongs to the group $C$. interrupta, the evolutionary history of which has been thoroughly explored (Termonia et al. 2001). Combining molecular phylogenetic analyses and data on defensive chemistry suggests that host-derived metabolism (i.e., sequestration of defensive compounds from SG-rich Salicaceae) is ancestral for this group (Termonia et al. 2001), but current host plant association of C. lapponica is variable. While some populations retain fidelity to SG-containing species [(including Populus tremula L. (Matis et al. 1980), Salix myrsinifolia Salisb. (Zvereva et al. 1995; Gross et al. 2004a) or S. fragilis L. (Warchalowski 1994)], some populations have switched to SG-poor Salicaceae, such as S. caprea L. (Kruglova and Zvereva 2006) and S. glauca L. (Virtanen et al. 2004), or to SG-free plants belonging to other families including Rosaceae (bird cherry Prunus padus L. and dog rose Rosa canina L.: Matis et al. 1980), and Betulaceae (alder Alnus viridis DC.: Leplat 1999; and different birch species: Matis et al. 1980; Gross and Hilker 1994; Hilker and Schulz 1994).

In this study, we tested the hypothesis that populations of $C$. lapponica associated with either SG-rich or SG-poor hosts demonstrate local adaptations to their natural host plants with respect to life history traits. We used the approach outlined by Kawecki and Ebert (2004) who regarded the 'local versus foreign' criterion as diagnostic for patterns of local adaptation; according to this criterion, each population shows increased fitness in its habitat relative to foreign populations introduced to that habitat. Following Via (1991), we considered a host plant species a local habitat. Host plant quality needs consideration in analysis of host plant specialization (Via 1990), since it is an important bottom-up factor affecting herbivore fitness and herbivore efficiency to cope with top-down factors such as pathogens, parasitoids, and predators.

To test our hypothesis, we recorded in laboratory-rearing experiments the performance of individuals from five different $C$. lapponica populations on (1) their natural host plant (=local habitat; i.e., willow species used by beetles of the investigated population in their native habitat) and (2) on a foreign host plant (i.e., willow species present in the native habitat, but not used by beetles of the respective population); natural and foreign host plants fed to the beetles had contrasting SG-content. Two of the five populations studied are associated in nature with ancestral SGrich hosts, and the three other populations are naturally associated with novel SG-poor host plants. In accordance with our hypothesis, we expected populations living in nature on SG-rich hosts to show better performance on the SG-rich plant, whereas populations living in nature on SGpoor hosts were expected to perform better on the SG-poor willow than on the SG-rich one.

\section{Materials and methods}

The study object

The leaf beetle $C$. lapponica is widely distributed in the Palaearctic region (Matis et al. 1980; Warchalowski 1994) and capable of occasionally causing severe defoliation of its host plants (Warchalowski 1994; Zvereva et al. 1997). This species is univoltine and demonstrates substantial variation in color pattern. Adults hibernate in soil and start feeding and copulating on host plants soon after leaf flush. Females lay clutches of 35-40 eggs on host plant leaves. Larvae feed for about 1 month and pupate on their host plants.

Populations and host plants

Five populations of $C$. lapponica associated with different host plants in nature were used (Table 1):

(1) Kola population: beetles were collected on Kola Peninsula, Russia, near Nikel $\left(69^{\circ} 24^{\prime} \mathrm{N}, 30^{\circ} 13^{\prime} \mathrm{E}\right)$. This population feeds almost exclusively (85-100\%; Zvereva et al. 1995) on $S$. myrsinifolia subsp. 
Table 1 Willow (Salix spp.) and poplar (Populus spp.) species common in studied localities and their use by Chrysomela lapponica in natural conditions and in laboratory experiments

\begin{tabular}{|c|c|c|c|}
\hline $\begin{array}{l}\text { Geographical } \\
\text { region }\end{array}$ & $\begin{array}{l}\text { Local species used by leaf beetle in nature } \\
\text { (SG content) }^{\mathrm{a}}\end{array}$ & $\begin{array}{l}\text { Local species not used by leaf beetle in nature } \\
\text { (SG content) })^{\mathrm{a}}\end{array}$ & $\begin{array}{l}\text { Plants used for rearing in the } \\
\text { laboratory }{ }^{b}\end{array}$ \\
\hline $\begin{array}{l}\text { Kola } \\
\text { Peninsula }\end{array}$ & S. myrsinifolia (SG-rich) & $\begin{array}{l}\text { S. caprea (SG-poor) } \\
\text { S. glauca (SG-poor) } \\
\text { S. phylicifolia (SG-poor) }\end{array}$ & $\begin{array}{l}\text { S. myrsinifolia } \text { (SG-rich) } \\
\text { S. caprea (SG-poor) }\end{array}$ \\
\hline Finland & S. myrsinifolia (SG-rich) & $\begin{array}{l}\text { S. caprea (SG-poor) } \\
\text { S. glauca (SG-poor) } \\
\text { S. phylicifolia (SG-poor) }\end{array}$ & $\begin{array}{l}\text { S. myrsinifolia } \text { (SG-rich) } \\
\text { S. caprea (SG-poor) }\end{array}$ \\
\hline Belarus & S. caprea (SG-poor) & $\begin{array}{l}\text { S. myrsinifolia (SG-rich) } \\
\text { S. fragilis (SG-poor) } \\
\text { S. aurita (SG-poor) } \\
\text { S. cinerea (SG-poor) }\end{array}$ & $\begin{array}{l}\text { S. myrsinifolia (SG-rich) } \\
\text { S. caprea (SG-poor) }\end{array}$ \\
\hline Baikal & $\begin{array}{l}\text { S. caprea (SG-poor) } \\
\text { S. glauca (SG-poor) } \\
\text { S. rorida (SG-poor) } \\
\text { S. dasyclados (SG-poor) } \\
\text { P. suaveolens (SG-rich) }\end{array}$ & Not found among common species & $\begin{array}{l}\text { S. myrsinifolia (SG-rich) } \\
\text { S. caprea (SG-poor) }\end{array}$ \\
\hline Ural & $\begin{array}{l}\text { S. dasyclados (SG-poor) } \\
\text { S. glauca (SG-poor) } \\
\text { S. phylicifolia (SG-poor) } \\
\text { S. lanata (SG-poor) }\end{array}$ & Not found among common species & $\begin{array}{l}\text { S. myrsinifolia (SG-rich) } \\
\text { S. caprea (SG-poor) } \\
\text { S. glauca (SG-poor) }\end{array}$ \\
\hline
\end{tabular}

$S G$ Salicylic glycoside

${ }^{\text {a }}$ Classification is based mostly on Julkunen-Tiitto (1989, and personal communication)

b Native plant species in bold

borealis (Fr.) Hyl., a plant with high concentrations of SGs (40-80 mg/g of salicortin; Julkunen-Tiitto 1989). SG-poor S. caprea plants are common in this locality, but $C$. lapponica individuals were only very rarely found to feed on this plant species (Zvereva et al. 1995; personal observations of E. Zvereva and M. Kozlov in 1995-2008).

(2) Finland population: beetles were collected in Finnish Lapland near Nuorgam $\left(70^{\circ} 05^{\prime} \mathrm{N}, 27^{\circ} 51^{\prime} \mathrm{E}\right)$. The type of locality and beetle association with $S$. myrsinifolia are similar to the Kola population (Gross et al. 2004b).

(3) Belarus population: beetles were collected in the Berezinsky Reserve in Belarus $\left(54^{\circ} 30^{\prime} \mathrm{N}, 28^{\circ} 45^{\prime} \mathrm{E}\right)$, where they feed almost exclusively (94\%: Kruglova and Zvereva 2006) on S. caprea, a plant with very low concentrations of SGs (traces to $0.7 \mathrm{mg} / \mathrm{g}$ of salicortin; Julkunen-Tiitto 1989; Soetens et al. 1998). SG-rich $S$. myrsinifolia plants are common in this locality, but are not used by C. lapponica (Kruglova and Zvereva 2006).

(4) Baikal population: beetles were collected near Baikalsk $\left(51^{\circ} 30^{\prime} \mathrm{N}, 104^{\circ} 14^{\prime} \mathrm{E}\right)$ in Russia. Salix myrsinifolia does not grow in this locality, but there is another Salicaceae species growing in the habitat, Populus suaveolens Fisch., which is as rich in SG content as $S$. myrsinifolia (R. Julkunen-Tiitto, personal communication). Most of the beetles (43\%) were found on $S$. caprea, the rest of population was distributed on other abundant SG-poor species ( $S$. rorida Laksch., 23\%; $S$. dasyclados Wimm., 18\%) and regrowth of poplar ( $P$. suaveolens, $16 \%$ ).

(5) Ural population: beetles were collected in Polar Ural, Russia, near Vorkuta $\left(67^{\circ} 03^{\prime} \mathrm{N}, 63^{\circ} 34^{\prime} \mathrm{E}\right)$ and were found feeding mainly on two willow species: $S$. dasyclados and $S$. glauca, which both have low concentrations of SGs (9.3 and $3.8 \mathrm{mg} / \mathrm{g}$ of salicortin, respectively; Julkunen-Tiitto 1989). No willow species with high SG concentrations were discovered in the surveyed habitats of this population.

Observations on field distributions of adult beetles and larvae among host plants were conducted during at least two seasons for each population.

Larval performance in relation to host plants

To account for within-population genetic variation, we used a family-design with larval families originating from 
field-collected mated females. Overwintered females were collected in spring from each of the five populations (Finland, Kola, Belarus, Baikal, and Ural), transported to Apatity (Murmansk region, NW Russia), and kept individually in Petri dishes on their natural hosts to get one batch per female. The number of batches varied from 5 to 15 depending on the population and experiment. Larvae hatching from an egg batch (25-40 per batch) were divided into two groups of equal size. One of these groups was reared on SG-rich $S$. myrsinifolia, and the other group was reared on SG-poor S. caprea. Thus, larvae of each population were reared on their natural host plant (i.e., plant species used by leaf beetles of the investigated population in their native habitat) and on a foreign host plant (i.e., plant species present in the native habitat, but not used by leaf beetles of the investigated population) with contrasting SG-content, except for the Ural population, because neither $S$. myrsinifolia nor $S$. caprea grow in this locality (Table 1). Therefore, five additional families from the Ural population were reared on its native host, S. glauca. Newly hatched larvae were placed in 50-ml vials and fed with mature leaves collected from five field-growing individuals of each host plant species. Fresh leaves were added every second day. The experiments were terminated when young beetles emerged from pupae.

The following performance parameters were determined: (1) survival from hatching of larvae to emergence of adults, (2) duration of development from hatching of larvae to emergence of adults, and (3) weight of newly emerged beetles (determined by electronic balances to the nearest $0.1 \mathrm{mg}$ ). All performance trials were conducted at room temperature $\left(20^{\circ} \mathrm{C}\right)$ and natural illumination in a common laboratory environment. Survival was measured in 2008 (Baikal population) and in 2005 (all other populations). Duration of development and weight were measured in 2005 for the Ural population, in 2006 for the Finland, Belarus, and Kola populations, and in 2008 for the Baikal population.

\section{Data analysis}

Beetle survival was analyzed using logistic regression and the events/trials syntax with procedure LOGISTIC (SAS Institute 2003). In this case, trial was the number of hatched larvae in each experimental unit, and event was the number of emerged adults.

Data on beetle weight and duration of development were subjected to analysis of variance (ANOVA) (SAS Institute 2003) considering both population and host plant species (S. myrsinifolia and S. caprea) as fixed variables. For the Ural population, which was reared on three plant species (native $S$. glauca and two non-natives, SG-rich $S$. myrsinifolia and SG-poor S. caprea), an additional analysis of host plant effect was conducted. When required, variables were log-transformed prior to analyses to meet normality assumptions. Separate analyses of each population (with beetle family considered as random factor in a mixed model ANOVA) demonstrated that variation in the responses of different progenies to alternative host plants were not significant in all populations (data not shown). However, this result could be due to the low number of families (especially in the Ural population), and therefore we concentrated in the final analysis on differences between populations.

\section{Results}

Performance of $C$. lapponica, i.e., survival from larval hatching to adult emergence, duration of development during this time, and weight of newly emerged beetles, were significantly influenced by the plant species fed to larvae (Table 2). However, populations of $C$. lapponica differed in their response to SG-rich (S. myrsinifolia) and SG-poor ( $S$. caprea) willows as indicated by significant interaction between host plant and population for survival and duration of development (Table 2).

Three populations showed higher survival rates when reared on their native host plants than when reared on a foreign plant (Fig. 1a). Two of these populations (Finland and Kola) are associated in their natural habitat with SGrich $S$. myrsinifolia, and survival rates were higher when reared on this SG-rich plant than on the SG-poor plant, $S$. caprea. The third (Belarus) population is associated in its natural habitat with the SG-poor plant, S. caprea, and survival rates on this SG-poor plant were higher than on the foreign, SG-rich plant, S. myrsinifolia. In contrast, survival rates of the other populations tested (Baikal and Ural) were similar on native (SG-poor) and foreign (SG-rich) host plants (Fig. 1a).

Host plant effects on the duration of development were similar to the effects on survival for the Finland and Kola populations; in these populations, development from larvae to adults was significantly faster on the native SG-rich plant than on the foreign SG-poor plant. However, in the Belarus population, development time on the native SGpoor plant was similar to development time on the foreign SG-rich host plant. In the Baikal population, feeding on the native SG-low host plant even led to a significant prolongation of larval development compared to developmental time when feeding on the foreign SG-rich plant. In the Ural population, duration of development from larval hatching to adult emergence on two SG-poor species (native $S$. glauca and non-native $S$. caprea) did not differ from developmental time on the SG-rich $S$. myrsinifolia (Fig. 1b). 
Table 2 Effects of beetle population (Kola, Finland, Belarus, Ural, Baikal) and host plant species (Salix myrsinifolia vs S. caprea) on performance traits of leaf beetle Chrysomela lapponica

\begin{tabular}{|c|c|c|c|c|c|}
\hline Character & Sources of variation & $d f$ & MS & $F / W C H$ & $P$ \\
\hline \multirow[t]{3}{*}{ Survival $^{\mathrm{a}}$} & Beetle population & 4 & - & 34.82 & $<0.0001$ \\
\hline & Plant species & 1 & - & 13.62 & 0.0002 \\
\hline & Beetle population $\times$ plant species & 4 & - & 68.53 & $<0.0001$ \\
\hline \multirow[t]{4}{*}{ Weight of newly emerged beetles } & Beetle population & 4 & 9684 & 16.79 & $<0.0001$ \\
\hline & Plant species & 1 & 2741 & 4.75 & 0.03 \\
\hline & Beetle population $\times$ plant species & 4 & 753 & 1.31 & 0.27 \\
\hline & Error & 104 & 577 & - & - \\
\hline \multirow[t]{4}{*}{ Duration of development ${ }^{\mathrm{b}}$} & Beetle population & 4 & 12.90 & 10.65 & $<0.0001$ \\
\hline & Plant species & 1 & 33.59 & 27.74 & $<0.0001$ \\
\hline & Beetle population $\times$ plant species & 4 & 5.18 & 4.28 & 0.003 \\
\hline & Error & 104 & 1.21 & - & - \\
\hline
\end{tabular}

$F$, Fisher test, refers to ANOVAs used to analyse beetle weight and duration of development; $W C H$, Wald Chi-square, refers to logistic regression model used to analyze survival data

${ }^{a}$ Survival from hatching of larvae to emergence of adults

${ }^{\mathrm{b}}$ Duration of development from hatching of larvae to emergence of adults
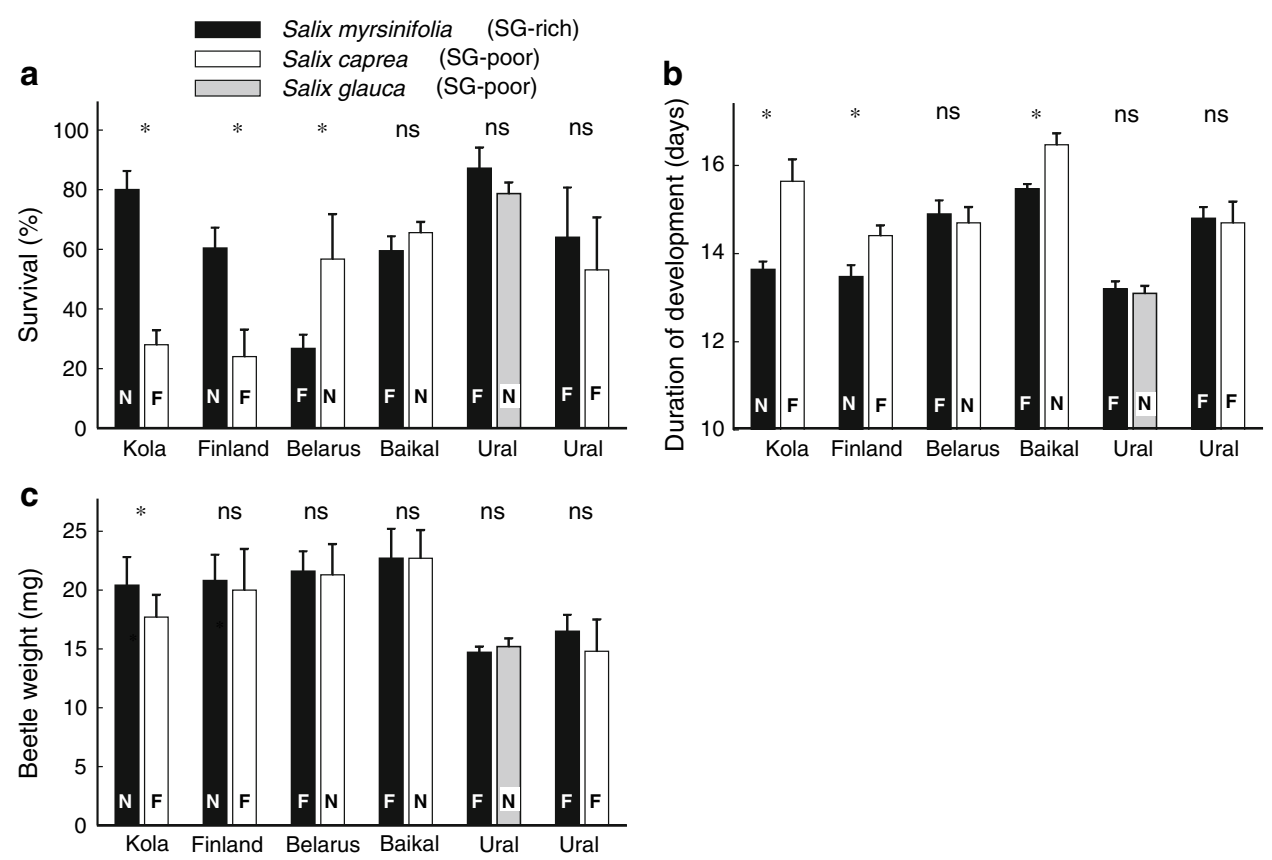

Fig. 1 Survival (a), duration of development (b) and beetle weight (c) in five populations of Chrysomela lapponica fed on host plants differing in salicylic glycoside (SG) concentrations. Means + SE are calculated from family-specific values (a $n=5$ families for Kola, Finland, Belarus, and Ural populations, and $n=10$ for Baikal population; $\mathbf{b}, \mathbf{c} n=15$ beetle families for Kola, Finland, and Belarus populations, $n=10$ for Baikal population, and $n=5$ for Ural population). Significant differences $(P<0.05)$ between host plant species are marked with asterisks (Chi-square test for survival,

The weight of beetles from the Kola population was lower when individuals had fed on the foreign host plant compared to beetles that had fed on the native host. In

Duncan test for duration of development and weight). $N$ Native host plant, i.e., species commonly used by this population in nature; $F$ foreign host plant, i.e., species not used by this population in nature. Individuals from the Finland, Kola, and Belarus populations performed better on native host species than on foreign host species, thus demonstrating local adaptations to a certain SG host-type. Individuals from the Baikal and Ural populations performed equally well on both native and foreign host plants, thus showing no specialization to a specific SG host-type

contrast, the weight of beetles from all other populations studied was independent of host plant species (Fig. 1c). 


\section{Discussion}

Three of five C. lapponica populations (from Finland, Kola, and Belarus) demonstrated local adaptations to host plants. Individuals from each of these populations showed increased survival when feeding on native rather than foreign host species. These results meet the 'local versus foreign' criterion (Kawecki and Ebert 2004). The significant interaction between effects of beetle population and host plant species on survival and duration of development of C. lapponica (Table 2) indicates that specialization of C. lapponica phenotypes to certain host plant species can maximize beetle fitness in their specific habitats.

Among the three populations which met the local adaptation criterion, two were adapted to the ancestral (SGrich) host plant (Finland, Kola), and one population (Belarus) developed adaptation to a novel SG-poor species. The level of local adaptation to the native host plant was higher in the populations adapted to the ancestral (SG-rich) host plant compared to the population adapted to a novel (SG-poor) host. In the latter population, only survival rates were higher on the native host, whereas duration of development and beetle weight did not differ from those on the foreign (ancestral) host. This difference may be explained by a much longer evolutionary history of adaptation to the ancestral host compared to the relatively short time since the shift to a novel host occurred.

Because feeding upon SG-rich hosts is ancestral to C. lapponica (Termonia et al. 2001), populations from Kola and Finland seem to exhibit an original type of host plant use. This ancestral specialization to SG-rich plants might have been favored by selection pressure by generalist enemies, since precursors sequestered from SG-rich host plants may be used by larvae to produce a defensive secretion that is highly efficient against generalist predators (Pasteels et al. 1983).

Populations of herbivorous insects are generally found to be specifically adapted to a novel host plant only when the original hosts are not present (e.g., Thompson 1993; Camara 1997; Ballabeni et al. 2003). Therefore, detection of local adaptation to SG-poor S. caprea in the Belarus population is of particular interest. In this population, more than $90 \%$ of egg batches of $C$. lapponica were found on $S$. caprea, although ancestral SG-rich S. myrsinifolia plants were equally abundant in the same habitats (Kruglova and Zvereva 2006). Significant genetic divergence of the Belarus population of $C$. lapponica from ancestral ones is supported by the fact that this population exclusively consists of black color morphs, whereas all other populations in this study consisted of typical morphs (red-andblack pattern) or were polymorphic.

While the Belarus population shifted from SG-rich willow species to SG-poor willows, several European $C$. lapponica populations are known to have shifted to SGlacking birch (Gross and Hilker 1994; Hilker and Schulz 1994; Warchalowski 1994), even though an SG-rich willow ( $S$. fragilis) co-occurs in the localities of these populations (Gross et al. 2004b), and some other European populations of $C$. lapponica feed on $S$. fragilis (Warchalowski 1994). Moreover, birch populations of $C$. lapponica demonstrate a high level of specialization to their host plant, because they have lost their ability to survive on SGrich willows (Gross et al. 2004b). In contrast, some larvae of the Belarus population still survive on SG-rich S. myrsinifolia (Fig. 1). Significant genetic divergence of a birchfeeding $C$. lapponica population from a population specialized on SG-rich willows is suggested by laboratory crossing experiments that showed post-zygotic reproductive isolation (Fatouros et al. 2006).

Thus, the Finnish and Kola populations on ancestral hosts, as well as the Belarus and birch populations on novel host plants, are narrow specialists in their local communities. This conclusion is supported by the high preference of their native hosts in the field: about $90 \%$ of $C$. lapponica records are made on native host species (Zvereva et al. 1995; Kruglova and Zvereva 2006). In contrast, Baikal and Ural populations of $C$. lapponica perform similarly well on their native and foreign host plant, and thus do not demonstrate local adaptations to novel SG-poor hosts like the Belarus population shows. Observations on host plant use in nature revealed that beetles of the Baikal and Ural populations feed on a number of willow species (Table 1). In the Ural locality, all these willows contained low amounts of SGs, whereas SG-rich species were absent. In the Baikal locality, C. lapponica beetles and larvae were found not only on several SG-poor willow species (Table 1), but also on regrowth of poplar, P. suaveolens, which is very rich in SGs (R. Julkunen-Tiitto, personal communication). SG-rich plants are usually consumed only by specialists, because SGs are toxic or deterrent for generalist herbivores (Ruuhola et al. 2001). Using both SGpoor and SG-rich hosts in nature indicates a certain level of generalization in host plant use. Thus, while the Belarus population demonstrated a clear shift to an SG-poor host plant, both the Ural and Baikal populations increased their host plant range by including SG-poor hosts in their diet, and still used SG-rich hosts when they were available.

Interestingly, our data hint at a positive association between host plant specialization and colur polymorphism across the geographical range of $C$. lapponica. The populations of northern Europe tightly associated with $S$. myrsinifolia consist only of the typical red-andblack individuals (Zvereva et al. 2002). Only one (black) morph was found in the Belarus population feeding almost exclusively on $S$. caprea. At the same time, both populations with wider niche breadth (Baikal and Ural; 
Table 1) are polymorphic. The Baikal population, although dominated by the red-and-black morph, also includes black individuals; and a variety of color morphs (black, red-and-black, and yellow with a number of intermediate morphs) were found in the Ural population (E. Zvereva, personal observation). This observation is in line with the hypothesis by Forsman et al. (2008) that polymorphism promotes utilization of diverse environmental resources, colonization success, and range expansion.

Among selective factors affecting host specialization (reviewed by Jaenike 1990), a shift from SG-rich to SGpoor hosts may be favored by the impact of specialist natural enemies (Gross et al. 2004a). Some natural enemies have evolved the ability to use salicylaldehyde, a major host plant-derived compound of larval defensive secretion, as a kairomonal cue to search for their prey (Gross et al. 2004a; Zvereva and Rank 2004). When feeding on SGpoor or SG-free host plants, $C$. lapponica release low amounts or no salicylaldehyde with their secretion. Thus, enemies specialized to use salicylaldehyde as kairomone are missing a crucial cue to locate prey. It has been suggested that $C$. lapponica feeding upon an SG-poor host could obtain enemy-free space from specialist enemies (Gross et al. 2004a). On the other hand, broadening of diet range and developing the ability to use SG-poor hosts in addition to SG-rich ones (as has been observed for the Ural and Baikal populations) might also be determined by resource availability (Jaenike 1990; Nosil et al. 2002) and the absence (Ural) or rarity (Baikal) of original SG-rich host plants.

In general, our results indicate that within one herbivore species host plant shift can be accompanied by the development of local adaptation and specialization to the novel host differing in secondary chemistry, as well as by incorporation of a novel species into host plant range by increasing the feeding niche breadth. Thus, the levels of specialization and adaptation may differ between populations of one species. Our results on C. lapponica are in line with the conclusions of Fox and Morrow (1981) that diet breadth is a local phenomenon and a characteristic trait rather of a population than of a species. Thus, adaptation strategies to novel host plants may differ between populations of a single species and reflect the very local conditions.

Acknowledgments We thank V. Zverev, O. Kruglova, and S. Didorenko for assistance in collecting material for the experiments, $\mathrm{R}$. Julkunen-Tiitto for analyzing the SGs in plant material, V. Chepinoga for determination of plant species from Baikal, and an anonymous reviewer for helpful comments. The study was supported by the Maj and Tor Nessling foundation through research grants to E. Zvereva, by the EC through the BALANCE project carried out under contract EVK2-2002-00169, and by the Academy of Finland (researcher exchange grants to E. Zvereva and researcher post of M. Kozlov). We thank the German Research Foundation (DFG) for a grant to $\mathrm{M}$. Hilker. The experiments comply with the current laws of Finland.

\section{References}

Ballabeni P, Gotthard K, Kayumba A, Rahier M (2003) Local adaptation and ecological genetics of host-plant specialization in a leaf beetle. Oikos 101:70-78

Bernays E, Graham M (1988) On the evolution of host specificity in phytophagous arthropods. Ecology 69:886-892

Brown WJ (1956) The new world species of Chrysomela L. (Coleoptera: Chrysomelidae). Can Entomol 88:1-54

Camara MD (1997) A recent host range expansion in Junonia coenia Hübner (Nymphalidae): oviposition preference, survival, growth, and chemical defense. Evolution 5:873-884

Dobler S, Mardulyn P, Pasteels JM, Rowell-Rahier M (1996) Hostplant switches and the evolution of chemical defense and life history in the leaf beetle genus Oreina. Evolution 50:2373-2386

Egas M, Sabelis MW, Dieckmann U (2005) Evolution of specialization and ecological character displacement of herbivores along a gradient of plant quality. Evolution 59:507-520

Fatouros NE, Hilker M, Gross J (2006) Reproductive isolation between populations from Northern and Central Europe of the leaf beetle Chrysomela lapponica $\mathrm{L}$. Chemoecology 16:241-251

Fernandez P, Hilker M (2007) Host plant location by Chrysomelidae. Basic Appl Ecol 8:97-116

Forsman A, Ahnesjö J, Caesar S, Karlsson M (2008) A model of ecological and evolutionary consequences of color polymorphism. Ecology 89:34-40

Fox LR, Morrow PA (1981) Specialization: species property or local phenomenon? Science 211:887-893

Funk DJ, Futuyma DJ, Orti G, Meyer A (1995) A history of host associations and evolutionary diversification for Ophraella (Coleoptera, Chrysomelidae)—new evidence from mitochondrial DNA. Evolution 49:1008-1017

Futuyma DJ, McCafferty SS (1990) Phylogeny and the evolution of host plant associations in the leaf beetle genus Ophraella (Coleoptera, Chrysomelidae). Evolution 44:1885-1913

Futuyma DJ, Moreno G (1988) The evolution of ecological specialization. Annu Rev Ecol Syst 19:207-233

Gross J, Hilker M (1994) Chemoecological studies of the exocrine glandular larval secretions of two chrysomelid species (Coleoptera): Phaedon cochleariae and Chrysomela lapponica. Chemoecology 5:185-189

Gross J, Fatouros NE, Neuvonen S, Hilker M (2004a) The importance of specialist natural enemies for Chrysomela lapponica in pioneering a new host plant. Ecol Entomol 29:584-593

Gross J, Fatouros NE, Hilker M (2004b) The significance of bottomup effects for host plant specialization in Chrysomela leaf beetles. Oikos 105:368-376

Hilker M, Schulz S (1994) Composition of larval secretion of Chrysomela lapponica (Coleoptera, Chrysomelidae) and its dependence on host-plant. J Chem Ecol 20:1075-1093

Jaenike J (1990) Host specialization in phytophagous insects. Annu Rev Ecol Syst 21:243-273

Julkunen-Tiitto R (1989) Phenolic constituents of Salix: a chemotaxonomic survey of further Finnish species. Phytochemistry 28:2115-2125

Kawecki TJ, Ebert D (2004) Conceptual issues in local adaptation. Ecol Lett 7:1225-1241

Kearsley MJC, Whitham TG (1992) Guns and butter-a no cost defense against predation for Chrysomela confluens. Oecologia 92:556-562 
Kelley ST, Farrell BD (1998) Is specialization a dead end? The phylogeny of host use in Dendroctonus bark beetles (Scolytidae). Evolution 52:1731-1743

Kruglova OYu, Zvereva EL (2006) Willow-feeding leaf beetles of Berezinski Biosphere Reserve: distribution among habitats and host plant specialization. In: Ivkovich VS (ed) Natural reserves of Belarus. Research, vol 1. Belarussian Printing House, Minsk, pp 234-240 (in Russian)

Leplat J (1999) Quelques observations sur Melasoma lapponica Linné (Coleoptera Chrysomelidae). Rutilans 2:82-83 (in French)

Margraf N, Verdon A, Rahier M, Naisbit RE (2007) Glacial survival and local adaptation in an alpine leaf beetle. Mol Ecol 16:23332343

Matis EG, Medvedev LN, Korotyaev BA, Glushkova LA (1980) Leaf beetles (Coleoptera: Chrysomelidae) of Okhotsko-Kolymsky mountains. In: Medvedev GS, Matis EG (eds) Investigations of insect fauna of North-East USSR. Institute for Biological Problems of the North, Vladivostok, pp 51-76 (in Russian)

Mayr E (1963) Animal species and evolution. Harvard University Press, Cambridge

Nosil P, Crespi BJ, Sandoval CP (2002) Host-plant adaptation drives the parallel evolution of reproductive isolation. Nature 417:440 443

Pasteels JM, Gregoire JC, Rowell-Rahier M (1983) The chemical ecology of defense in arthropods. Annu Rev Entomol 28:263289

Rensch B (1980) Historical development of the present synthetic neoDarwinism in Germany. In: Mayr E, Provine W (eds) The evolutionary synthesis: perspectives on the unification of biology. Harward University Press, Cambridge, pp 284-303

Rowell-Rahier M, Pasteels JM (1986) Economics of chemical defense in Chrysomelinae. J Chem Ecol 12:1189-1203

Ruuhola TM, Sipura M, Nousiainen O, Tahvanainen J (2001) Systemic induction of salicylates in Salix myrsinifolia (Salisb.). Ann Bot 88:483-497

SAS Institute (2003) SAS/STAT users guide. Version 9.1. SAS Institute, Cary, North Carolina

Schulz S, Gross J, Hilker M (1997) Origin of the defensive secretion of the leaf beetle Chrysomela lapponica. Tetrahedron 53:92039212

Smiley JT, Horn JM, Rank NE (1985) Ecological effects of salicin at three trophic levels - new problems from old adaptations. Science 229:649-651
Soetens P, Pasteels JM, Daloze D, Kaisin M (1998) Host plant influence on the composition of the defensive secretion of Chrysomela vigintipunctata larvae (Coleoptera: Chrysomelidae). Biochem Syst Ecol 26:703-712

Termonia A, Pasteels JM (1999) Larval chemical defense and evolution of host shifts in Chrysomela leaf beetle. Chemoecology 9:13-23

Termonia A, Hsiao TH, Pasteels JM, Milinkovitch MC (2001) Feeding specialization and host-derived chemical defense in Chrysomeline leaf beetles did not lead to an evolutionary dead end. Proc Natl Acad Sci USA 98:3909-3914

Thompson JN (1993) Preference hierarchies and the origin of geographical specialization in host use in swallowtail butterflies. Evolution 47:1585-1594

Via S (1990) Ecological genetics and host adaptation in herbivorous insects - the experimental study of evolution in natural and agricultural systems. Annu Rev Entomol 35:421-446

Via S (1991) The genetic structure of host plant adaptation in a spatial patchwork: demographic variability among reciprocally transplanted pea aphid clones. Evolution 45:827-852

Virtanen T, Mikkola K, Nikula A (2004) Satellite image based vegetation classification of a large area using limited ground reference data: a case study in the Usa Basin, north-east European Russia. Polar Res 23:51-66

Warchalowski A (1994) Chrysomelidae. Stonkowate (Insecta: Coleoptera). Museum i Instytutu Zoologii, Warszawa (in Polish)

Zvereva EL, Rank NE (2004) Fly parasitoid Megaselia opacicornis uses defensive secretions of the leaf beetle Chrysomela lapponica to locate its host. Oecologia 140:516-522

Zvereva EL, Kozlov MV, Neuvonen S (1995) Decrease in feeding niche breadth of Melasoma lapponica (Coleoptera: Chrysomelidae) with increase in pollution. Oecologia 104:323-329

Zvereva EL, Kozlov MV, Niemelä P, Haukioja E (1997) Delayed induced resistance and increase in leaf fluctuating asymmetry as responses of Salix borealis to insect herbivory. Oecologia 102:368-373

Zvereva EL, Kozlov MV, Kruglova OYu (2002) Color polymorphism in relation to population dynamics of the leaf beetle Chrysomela lapponica. Evol Ecol 16:523-539 